\title{
ANTIQUE CERAMIC IMPORT ON SETTLEMENTS OF SCYTHIAN TIME IN THE DON FOREST-STEPPE: CARTOGRAPHICAL RESEARCH ${ }^{1}$
}

\author{
Yuriy D. Razuvaev \\ Voronezh State Pedagogical University, Voronezh, Russian Federation
}

\begin{abstract}
In the article on the basis of the data obtained during excavation the author analyzes spatial distribution of ceramic import on household monuments of the 6th-3rd centuries BC in forest-steppe Podonye. This region is included into an area of Gorodetz and Scythian-like archaeological cultures. It is established that on settlements of Gorodetz culture import is practically absent. Fragments of products of the Greek potters (about 800 findings are considered) are present only on some settlements of Scythian-like culture. Mainly these are fragments of amphoras of various production centers (Bospor, Gerakley, Kos, Sinope, Fasos, etc.) and parts of table vessels (constitute less than $2 \%$ of findings). On settlements a little antique ceramics is found, as a rule: some fragments, and usually even less than the share of 100 square meters of the dug-out area. The saturated layer allocates only three big hillforts (Storozhevoe, Voloshino, Kirovskoe) which were obviously large shopping centers.

Mapping of the available data doesn't confirm the hypothesis of delivery of import which is earlier stated by researchers on the Don River. Existence of overland ways on which trade with the South was performed is more probable. An important communication role was played in the ancient time by water separate roads, known on medieval sources under the name of the Muravsky way. Its branch - the Kalmiussky sakma - passed just in the district of two hillforts (Voloshino, Kirovskoe) which are sharply allocated with quantity of the found fragments of amphoras.
\end{abstract}

Key words: forest-steppe Don region, Scythian era, antique ceramic import, settlements, trade ways.

Citation. Razuvaev Yu.D. Antique ceramic import on settlements of Scythian time in the Don forest-steppe: cartographical research. Vestnik Volgogradskogo gosudarstvennogo universiteta. Serija 4, Istorija. Regionovedenie. Mezhdunarodnye otnoshenija [Science Journal of Volgograd State University. History. Area Studies. International Relations], 2017, vol. 22, no. 2, pp. 15-24. (in Russian).

\section{АНТИЧНЫЙ КЕРАМИЧЕСКИЙ ИМПОРТ \\ НА ПОСЕЛЕНИЯХ СКИФСКОГО ВРЕМЕНИ В ДОНСКОЙ ЛЕСОСТЕПИ: КАРТОГРАФИЧЕСКОЕ ИССЛЕДОВАНИЕ ${ }^{1}$}

\author{
Юрий Дмитриевич Разуваев \\ Воронежский государственный педагогический университет, г. Воронеж, Российская Федерация
}

\footnotetext{
Аннотация. В статье на основе полученных при раскопках данных анализируется пространственное распределение керамического импорта на бытовых памятниках VI-III вв. до н. э. в лесостепном Подонье. Установлено, что на распространенных в регионе поселениях городецкой культуры он практически отсутствует. Фрагменты изделий греческих гончаров (учтено около 800 находок) встречены лишь на поселениях скифоидной культуры, причем не на всех. Преимущественно это обломки амфор различных производственнаходок). На поселениях найдено, как правило, относительно немного античной керамики: на 100 квадратных метров раскопанной площади приходилось лишь несколько фрагментов, а обычно даже менее одного. Насыщенным слоем выделяются только три больших городища (Сторожевое, Волошино, Кировское), явно являв-
} 
шихся крупными торговыми центрами. Картографирование имеющихся данных не подтверждает ранее высказанную исследователями гипотезу о доставке импорта по р. Дон. Более вероятно существование сухопутных путей, по которым осуществлялась торговля с югом.

Ключевые слова: лесостепное Подонье, скифская эпоха, античный керамический импорт, поселения, торговые пути.

Цитирование. Разуваев, Ю. Д. Античный керамический импорт на поселениях скифского времени в донской лесостепи: картографическое исследование / Ю. Д. Разуваев // Вестник Волгоградского государственного университета. Серия 4, История. Регионоведение. Международные отношения. - 2017. - Т. 22 , № 2. - C. $15-24$.

Уже после раскопок Мастюгинских и Частых курганов тесные контакты населения Среднего Дона с северопричерноморскими городами стали вполне очевидны [32, с. 538; 35 , с. 68]. За истекшее с тех пор столетие предметов античного происхождения в донской лесостепи найдено довольно много. В курганных погребениях, даже ограбленных, это ценные и престижные вещи, на стационарных поселениях - фрагменты керамики, обычно тарной, и стеклянные бусы. В этой диспропорции, надо полагать, отразилась историко-культурная ситуация, существовавшая в донской лесостепи в VI-III вв. до нашей эры. Сейчас в местной археологии утвердилось [22, с. 132], правда, не без дискуссии [12, с. 135-136], понимание этносоциальной разнородности курганных некрополей полукочевой знати и поселков оседлого населения.

Богатый импорт из среднедонских курганов неплохо изучен, чего нельзя сказать о поселенческих материалах, сводка каковых производилась лишь в конце 1960-х годов [28, c. 79-80]. Между тем о торгово-обменных связях находки с бытовых памятников говорят более красноречиво, нежели курганный инвентарь, куда попадали и военные трофеи, и подарки.

Степень исследованности региона сейчас такова, что можно попытаться проанализировать ассортимент и пространственное распределение дошедших до оседлого населения привозных изделий. Прежде всего речь идет о греческой керамике, имеющей исключительное значение в изучении торговых контактов [9, с. 21-22].

Предваряя рассмотрение вопроса, заметим, что в VI-III вв. до н. э. на Среднем и Верхнем Дону соседствовали носители двух культурных традиций: лесостепной скифоидной и лесной городецкой. Их поселения в ка- ких-то проявлениях материальной культуры различны, в других схожи. Доступность импорта - наглядный показатель степени конвергентности двух этносов.

По всему донскому ареалу обеих культур к настоящему времени исследованы десятки городищ и неукрепленных поселков. Из них для картографирования отобраны порядка полусотни - те, где вскрыта более-менее существенная площадь и получены достаточно выразительные материалы скифской эпохи. По отчетам и публикациям либо музейным коллекциям собрана доступная информация о найденных при раскопках обломках античных амфор и столовых сосудов - всего таковых оказалось около 800 (см. таблицу) ${ }^{2}$.

К сожалению, лишь часть этих материалов анализировалась специалистами. Но и по имеющимся определениям видно, что античная керамика поступала в лесостепное Подонье со второй половины VI в. до н. э. вплоть до конца скифской эпохи. Причем преимущественно это была амфорная тара - фрагменты столовых сосудов составляют менее $2 \%$ от общего числа находок. Судя по производственным центрам (Боспор, Византий, Гераклея, Кос, Синопа, Трапезунд, Фасос, Хиос и др.), ассортимент ввозимых товаров был един для днепро-донской лесостепи $[1 ; 13]^{3}$.

Почти на половине рассматриваемых памятников находки импортной керамики вообще отсутствовали. А там, где имелись, их количество весьма различно: от одного фрагмента до нескольких сотен. Разумеется, на этот показатель сильно влияют специфика формирования и несовершенство археологического изучения культурных напластований. Однако в целом он все же показывает степень насыщенности слоя фрагментами античной керамики. Наглядное представление о ней дает коэффициент пропорциональности: чис- 
Ю.Д. Разуваев. Античный керамический импорт на поселениях скифского времени

Античная керамика на поселениях скифской эпохи в донской лесостепи

\begin{tabular}{|c|c|c|c|c|c|c|c|c|}
\hline \multirow{2}{*}{$\begin{array}{c}\text { № на } \\
\text { карте } \\
\text { (рису- } \\
\text { нок) }\end{array}$} & \multirow[t]{2}{*}{ Памятник } & \multirow{2}{*}{$\begin{array}{c}\text { Общая } \\
\text { раско- } \\
\text { панная } \\
\text { площадь } \\
\text { (кв. м) }\end{array}$} & \multicolumn{2}{|c|}{$\begin{array}{l}\text { Фрагменты ан- } \\
\text { тичной керамики }\end{array}$} & \multirow{2}{*}{$\begin{array}{c}\text { Коэф- } \\
\text { фици- } \\
\text { ент }\end{array}$} & \multirow{2}{*}{$\begin{array}{c}\text { Производ- } \\
\text { ственные } \\
\text { центры }\end{array}$} & \multirow{2}{*}{$\begin{array}{c}\text { Имею- } \\
\text { щиеся } \\
\text { датиров- } \\
\text { ки (вв. до } \\
\text { н. э.) }\end{array}$} & \multirow[t]{2}{*}{ Источник } \\
\hline & & & амфоры & $\begin{array}{c}\text { столо- } \\
\text { вые со- } \\
\text { суды } \\
\end{array}$ & & & & \\
\hline 1 & д. Дубики, гор. и сел.* & 498 & & & & & & \\
\hline 2 & с. Перехваль, гор.-2 & 214 & & & & & & \\
\hline 3 & д. Рябинки, гор. & 324 & & & & & & \\
\hline 4 & с. Нижний Воргол, гор. & 1724 & & & & & & \\
\hline 5 & с. Александровка, гор. & 568 & & & & & & \\
\hline 6 & с. Лавы, пос.-3 & 4961 & & & & & & \\
\hline 7 & с. Кривец, пос.-4 & 586 & & & & & & \\
\hline 8 & с. Делеховое, пос.-3 & 1370 & $?$ & & & & & \\
\hline 9 & с. Сырское, гор. & 668 & & & & & & \\
\hline 10 & $\begin{array}{l}\text { с. Крутогорье (уроч. } \\
\text { «Малый Лепяг»), гор. }\end{array}$ & 276 & & & & & & \\
\hline 11 & с. Верхнее Казачье, гор. & 759 & 3 & & 0,4 & Трапезунд & II-I & {$[30$, c. 87$]$} \\
\hline 12 & с. Каменка, пос. & 1264 & & & & & & \\
\hline 13 & с. Каменка, гор. & 200 & 1 & & 0,5 & & & {$[5$, c. 190$]$} \\
\hline 14 & с. Замятино, пос.-7 & 568 & & & & & & \\
\hline 15 & с. Замятино, пос.-8 & 658 & & & & & & \\
\hline 16 & с. Замятино, пос. -5 & 883 & 1 & & 0,1 & & IV & [6] \\
\hline 17 & с. Мухино, гор. & 196 & $?$ & & & & & \\
\hline 18 & с. Ксизово, пос.-17 & 4841 & & & & & & \\
\hline 19 & с. Ксизово, гор. & 144 & & & & & & \\
\hline 20 & с. Курино, пос.-1 & 562 & & & & & & \\
\hline 21 & с. Конь-Колодезь, гор. & 292 & 1 & & 0,3 & & $\mathrm{VI}-\mathrm{V}$ & {$[16$, c. 163$]$} \\
\hline 22 & с. Отскочное, гор. & 384 & 4 & & 1,0 & & & \\
\hline 23 & с. Сенное, гор. & 800 & 2 & & 0,3 & & $\begin{array}{l}\text { в. п. IV- } \\
\text { П. п. III } \\
\end{array}$ & $\begin{array}{l}\text { определение } \\
\text { С.Ю. Монахова }\end{array}$ \\
\hline 24 & с. Пекшево, гор. & 2676 & + & $?$ & $>1 ?$ & & в. п. VI & {$[22$, c. 84$]$} \\
\hline 25 & с. Ивницы, гор. & 185 & & & & & & \\
\hline 26 & $\begin{array}{l}\text { с. Староживотинное, } \\
\text { гор. (Животинное) }\end{array}$ & 2803 & + & $?$ & $>1 ?$ & & & \\
\hline 27 & с. Чертовицы, гор.-3 & св. 3000 & + & $?$ & $>1 ?$ & Фacoc & $\begin{array}{l}\text { в. п. V - } \\
\text { н. IV }\end{array}$ & {$[24$, c. 48$]$} \\
\hline 28 & с. Чертовицы, гор.-2 & 260 & 5 & & 1,9 & & & {$[19$, c. 113$]$} \\
\hline 29 & с. Чертовицы, гор.-1 & 120 & & & & & & \\
\hline 30 & с. Чертовицы, ст. & 347 & 3 & & 0,9 & & & \\
\hline 31 & $\begin{array}{l}\text { г. Воронеж (уроч. «Лы- } \\
\text { сая гора»), пос.-6 }\end{array}$ & 48 & 1 & 1 & 4 & Гераклея & IV & {$[21$, c. 76$]$} \\
\hline 32 & $\begin{array}{l}\text { г. Воронеж, гор. (Куз- } \\
\text { нецовское) }\end{array}$ & 183 & 2 & & 1 & & & {$[10$, c. 11$]$} \\
\hline 33 & $\begin{array}{l}\text { г. Воронеж, пос.-5 (Чи- } \\
\text { жовское) }\end{array}$ & 202 & & & & & & \\
\hline 34 & $\begin{array}{l}\text { с. Подгорное (уроч. } \\
\text { «Частые Курганы»), } \\
\text { пос.-3 }\end{array}$ & 604 & 35 & & 5,8 & Гераклея & IV-III & {$[28$, c. 80$]$} \\
\hline 35 & $\begin{array}{l}\text { с. Подгорное (уроч. } \\
\text { «Частые Курганы»), } \\
\text { пос.-5 }\end{array}$ & 192 & 2 & & 1 & & & \\
\hline 36 & с. Губарево, гор. & 134 & & & & & & \\
\hline 37 & г. Семилуки, гор. & 3774 & 4 & 2 & 0,2 & $\begin{array}{l}\text { Южнопон- } \\
\text { тийский } \\
\text { центр } \\
\end{array}$ & $\begin{array}{l}\text { IV, IV - } \\
\text { н. III, } \\
\text { п. п. III } \\
\end{array}$ & {$[27$, c. 58,66$]$} \\
\hline 38 & с. Петино, гор. & 276 & 3 & & 1,1 & $\begin{array}{c}\text { неизвест- } \\
\text { ный } \\
\text { центр }\end{array}$ & к. V & {$[29$, c. 80$]$} \\
\hline
\end{tabular}


Окончание таблицьь

\begin{tabular}{|c|c|c|c|c|c|c|c|c|}
\hline \multirow{2}{*}{$\begin{array}{c}\text { № на } \\
\text { карте } \\
\text { (рису- } \\
\text { нок) }\end{array}$} & \multirow[t]{2}{*}{ Памятник } & \multirow{2}{*}{$\begin{array}{c}\text { Общая } \\
\text { раско- } \\
\text { панная } \\
\text { площадь } \\
\text { (кв. м) }\end{array}$} & \multicolumn{2}{|c|}{$\begin{array}{c}\text { Фрагменты ан- } \\
\text { тичной керамики }\end{array}$} & \multirow{2}{*}{$\begin{array}{l}\text { Коэф- } \\
\text { фици- } \\
\text { ент }\end{array}$} & \multirow{2}{*}{$\begin{array}{l}\text { Производ- } \\
\text { ственные } \\
\text { центры }\end{array}$} & \multirow{2}{*}{$\begin{array}{l}\text { Имею- } \\
\text { щиеся } \\
\text { датиров- } \\
\text { ки (вв. до } \\
\text { н. э.) }\end{array}$} & \multirow[t]{2}{*}{ Источник } \\
\hline & & & амфоры & $\begin{array}{c}\text { столо- } \\
\text { вые со- } \\
\text { суды }\end{array}$ & & & & \\
\hline 39 & с. Устье, гор. & 252 & & & & & & \\
\hline 40 & с. Архангельское, гор. & $\begin{array}{l}\text { свыше } \\
1000\end{array}$ & $\begin{array}{c}\text { не- } \\
\text { сколько }\end{array}$ & & $<1$ & & IV-III & $\begin{array}{l}{[14, \text { c. } 59 ; 26,} \\
\text { c. } 87]\end{array}$ \\
\hline 41 & $\begin{array}{l}\text { с. Сторожевое Первое, } \\
\text { гор. (Большое) - pac- } \\
\text { копки 1961, 1962, } \\
2009 \text { гг. }\end{array}$ & 446 & 47 & 4 & 11,4 & $\begin{array}{l}\text { Кос, Фа- } \\
\text { сос, Хиос }\end{array}$ & $\begin{array}{c}\text { рубеж } \\
\text { VI-V, } \\
\text { IV-III, } \\
\text { III-II, } \\
\text { III-I }\end{array}$ & {$[28$, c. 80$]$} \\
\hline 42 & с. Россошки, гор.-1 & $\begin{array}{c}\text { свыше } \\
550\end{array}$ & 1 & & 0,2 & Хиос & $\begin{array}{c}430- \\
400 \text { гг. }\end{array}$ & {$[4$, c. 90$]$} \\
\hline 43 & хут. Титчиха, гор. & $\begin{array}{c}\text { свыше } \\
7000\end{array}$ & $?$ & 1 & $<1 ?$ & & & \\
\hline 44 & хут. Титчиха, пос.-2 & 452 & & 1 & 0,2 & & & {$[25$, рис. 1,11$]$} \\
\hline 45 & $\begin{array}{l}\text { с. Тишанка (уроч. } \\
\text { «Дрониха»), пос. }\end{array}$ & 948 & 2 & & 0,2 & $\begin{array}{l}\text { Протофа- } \\
\text { сос }\end{array}$ & $\mathrm{V}$ & {$[31$, c. 208$]$} \\
\hline 46 & хут. Аверино, гор. & 144 & 3 & & 2 & & & {$[34$, c. 155$]$} \\
\hline 47 & хут. Мостище, гор. & 3747 & 8 & 2 & 0,3 & & & {$[34$, c. 131$]$} \\
\hline 48 & с. Волошино, гор.-1 & 3761 & 525 & + & 14 & $\begin{array}{c}\text { Боспор, } \\
\text { Византий } \\
(?), \text { Ге-- } \\
\text { раклея, } \\
\text { Кос, не- } \\
\text { извест- } \\
\text { ный } \\
\text { центр, } \\
\text { Синопа, } \\
\text { Фасос, } \\
\text { Хиос }\end{array}$ & $\begin{array}{l}\text { IV, IV- } \\
\text { III, II }\end{array}$ & $\begin{array}{l}{[14, \text { c. } 59 ; 28,} \\
\text { c. } 80]\end{array}$ \\
\hline 49 & с. Волошино, гор.-2 & 178 & & & & & & \\
\hline 50 & $\begin{array}{l}\text { с. Русская Тростянка, } \\
\text { гор. }\end{array}$ & 342 & 11 & + & 3,2 & $\begin{array}{c}\text { Боспор, } \\
\text { Кос, не- } \\
\text { извест- } \\
\text { ный } \\
\text { центр, } \\
\text { Синопа, } \\
\text { Фасос, } \\
\text { Хиос }\end{array}$ & IV-III, II & {$[28$, c. $79-80]$} \\
\hline 51 & с. Круглое, гор. & 168 & 4 & & 2,4 & & V-IV (?) & \\
\hline 52 & $\begin{array}{l}\text { хут. Городище, гор. } \\
\text { (Кировское) }\end{array}$ & 336 & 98 & 4 & 30,4 & $\begin{array}{c}\text { Боспор, } \\
\text { Византий } \\
(?), \text { Ге-- } \\
\text { раклея, } \\
\text { Кос, не- } \\
\text { извест- } \\
\text { ный } \\
\text { центр, } \\
\text { Синопа, } \\
\text { Фасос, } \\
\text { Хиос }\end{array}$ & $\begin{array}{c}\text { рубеж } \\
\text { VI-V, V, } \\
\text { IV, IV- } \\
\text { III, III, } \\
\text { III-I }\end{array}$ & {$[28$, c. $79-80]$} \\
\hline 53 & $\begin{array}{l}\text { с. Верхняя Покровка, } \\
\text { гор. }-2\end{array}$ & 214 & 3 & & 1,4 & & & {$[18$, c. 137$]$} \\
\hline 54 & с. Стрелецкое, гор.-2 & 304 & 12 & & 3,9 & $\begin{array}{l}\text { Гераклея, } \\
\text { Фасос }\end{array}$ & IV-III & {$[33$, c. 174$]$} \\
\hline
\end{tabular}

Примечание. * - гор. - городище; пос. - поселение; сел. - селище; ст. - стоянка; уроч. - урочище. 
ло обломков на 100 раскопанных квадратных метров ${ }^{4}$. При значении его менее единицы слой поселения был оценен как слабо насыщенный, от 1 до 9 - средне насыщенный, 10 и более - сильно насыщенный ${ }^{5}$.

Местоположение и степень насыщенности слоя рассматриваемых поселений представлены на картосхеме, наглядно демонстрирующей общую картину распространения керамического импорта в регионе (см. рисунок). Визуализация показывает, что он присутствует практически только на скифоидных поселениях.
Лишь дважды городецкую «рогожную» керамику и амфорные обломки находили совместно, причем сопряженность их неочевидна. Так, горловина амфоры IV в. до н. э. обнаружена на поселении-5 у с. Замятино, рядом с которым есть и скифоидные памятники. На городецкой стоянке у с. Тишанка («Дрониха») обнаружены три фрагмента амфорных ручек V в. до н. э., а также бронзовый наконечник стрелы скифского типа. Интересно, что в округе того же села на дне р. Битюг была найдена косская амфора конца III - начала II в. до нашей эры $[3]^{6}$. Поэтому нельзя исклю-

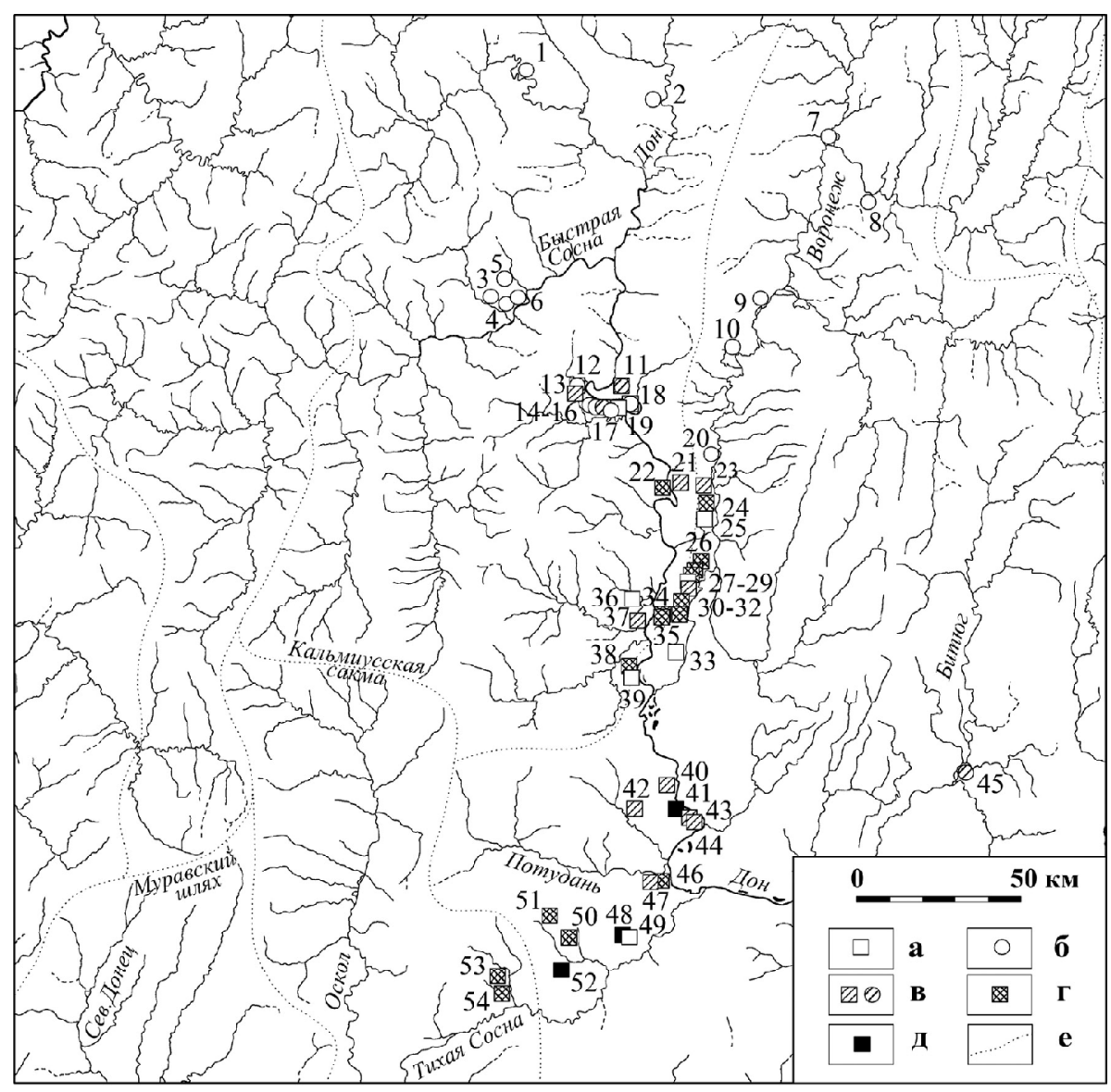

Основные поселения скифской эпохи в лесостепном Подонье (нумерация соответствует принятой в таблице):

$a$ - поселение скифоидной культуры; $\sigma$ - поселение городецкой культуры; в - поселения со слабо насыщенным античной керамикой слоем;

2 - поселения со средне насыщенным античной керамикой слоем;

$\partial$ - поселения с сильно насыщенным античной керамикой слоем; $e-$ средневековая дорога

Main settlements of the Scythian age in the forest-steppe Don region (the given numeration is complied with that in the table):

$a$ - settlement of Scythian culture; $b$ - settlement of Gorodets culture;

$v$ - settlements with the layer poorly saturated with antique ceramics;

$g$ - settlements with the layer moderately saturated with antique ceramics;

$d$ - settlements with the layer highly saturated with antique ceramics; $e$ - road of the Middle Ages 
чать, что в этих местах некогда существовала речная переправа, периодически использовавшаяся кочевниками.

Уже давно подмечено, что продукция греческих мастеров почти не проникала к обитателям леса [11, с. 148]. Надо полагать, это свидетельствует не только об отстраненности последних от дальних торговых маршрутов, но и о незначительности контактов с южными соседями.

В целом на скифоидных поселениях фрагменты античной керамики не являются массовым материалом: практически на каждом пятом из числа рассматриваемых они не найдены. Конечно, привозную посуду берегли, разбив же, иной раз чинили [34, с. 131]. Амфорные черепки нередко использовали в качестве лощил или абразивов [5, с. $190 ; 19$, с. $114 ; 20$, с. 9; 33, с. 174]. Но на Средний Дон греческой керамики поступало меньше, нежели в другие регионы скифской лесостепи [8, с. 101].

Одиннадцать поселений, то есть более трети тех, где присутствует амфорный материал (таковых всего 29), характеризуются слабо насыщенным слоем (коэффициент, как правило, 0,1-0,5). Да и среди 15 других находок, по имеющимся данным, не намного больше: от 1 до 4, лишь однажды более 5 фрагментов на 100 кв. м.

Радикально выделяются только три городища: Большое Сторожевое $(11,4)$, Волошино I (14) и Кировское $(30,4)$. Эти крупные и хорошо укрепленные поселения, несомненно, являлись значительными общественно-экономическими центрами. Большое Сторожевое городище находится на Дону. А вот два других удалены от этой реки по прямой на 22 и 42 км, а от впадающей в нее Тихой Сосны - на 11 км.

Некоторые исследователи полагают, что керамический импорт доставлялся по Дону [2, с. $186 ; 17$, с. $14 ; 23$, с. $136 ; 36$, с. 58]. Как представляется, в этом случае на приречных поселениях, особенно южных, соответствующих находок должно быть существенно больше, нежели на других. Однако такого не наблюдается. Казалось бы, обладающее насыщенным слоем Большое Сторожевое городище могло быть своего рода эмпорием на донском пути. Но по количеству привозной посуды оно уступает двум сугубо «сухопутным» укрепленным поселениям.
Предложенный в свое время И.Б. Брашинским [8, с. 103] маршрут по Северскому Донцу, его притокам и Тихой Сосне также не подтверждается нашими данными. Находящиеся в левобережной части бассейна Сосны городища, за двумя упомянутыми исключениями, не богаче импортом некоторых других поселений региона. Да и поселения, непосредственно расположенные вдоль этого гипотетического речного пути, не отличаются обилием амфорного материала [22, с. 59].

Важную роль в экономических связях северопричерноморских народов исследователи отводят сухопутным маршрутам. Так, поступление керамического импорта на Средний Дон связывается с ольвийским торговым путем [14, с. 52].

Большое значение в коммуникации лесостепной Скифии с югом имели и водораздельные дороги, такие как известный по средневековым источникам Муравский шлях [1, с. 6-9; 7 , с. 35,$38 ; 13$, с. $41 ; 37$, с. $20-24]$. Одно из его ответвлений - Кальмиусская сакма - проходило через Тихую Сосну [15, с. 67], примерно там, где находятся наиболее богатые керамическим импортом городища Кировское и Волошино I, которые были, скорее всего, основными центрами сухопутной торговли в донской лесостепи.

\section{ПРИМЕЧАНИЯ}

1 Работа подготовлена при финансовой поддержке РГНФ по проекту № 15-01-00103а.

${ }^{2}$ Подъемный материал количественно не учитывался.

${ }^{3}$ Хотя сравнительных данных мало [2], все же отметим, что в среднедонских курганных могильниках найдено несколько амфор из центров (Колхида, Менда), пока не представленных на местных поселениях.

4 За неимением лучшего использование этого условного показателя представляется оправданным, хотя практика показывает, как сильно может варьировать количество находок по участкам поселения.

${ }^{5}$ На трех многослойных городищах (у с. Пекшево, Староживотинное, Чертовицы), относящихся также и к началу нашей эры, определения основного амфорного материала не производилось. Исходя из того, что максимально возможное количество обломков скифского времени не превышало нескольких десятков, городища условно отнесены к памятникам со средне насыщенным слоем.

${ }^{6}$ Амфора определена С.Ю. Монаховым, в публикации приводится иная датировка. 


\section{СПИСОК ЛИТЕРАТУРЫ}

1. Бандуровский, А. В. О путях проникновения античного импорта в верховья Северского Донца в скифскую эпоху (по материалам раскопок и разведок последних лет) / А. В. Бандуровский // Археологічні видкриття в Україні 1999-2000 pp.Київ : ІА НАНУ, 2001. - С. 5-10.

2. Безматерных, А. Е. Античные амфоры в курганах скифского времени лесостепного Дона / А. Е. Безматерных // Норция. - 2004. - Вып. IV. C. 178-192.

3. Безматерных, А. Е. Косская амфора из р. Битюг Воронежской области / А. Е. Безматерных // Боспорский феномен. Искусство на периферии античного мира : материалы Междунар. науч. конф. - СПб. : Нестор-История, 2009. - С. 464-468.

4. Белая, Н. Н. Городище Россошки I на Среднем Дону / Н. Н. Белая, А. А. Шевченко // Краткие сообщения Института археологии. - 2016. - № 242. C. $81-95$.

5. Бирюков, И. Е. Городище скифского времени у с. Каменка на Верхнем Дону / И. Е. Бирюков, Ю. Д. Разуваев // Археологические памятники бассейна Дона. - Воронеж : Изд-во Воронежского педуниверситета, 2004. - С. 181-191.

6. Бирюков, И. Е. Отчет отряда по изучению памятников раннего железного века археологической экспедиции Липецкой госдирекции по охране культурного наследия области в 1997 г. / И. Е. Бирюков // Архив Института археологии РАН. - Р. 1. № 21404 .

7. Болтрик, Ю. В. Сухопутные коммуникации Скифии (по материалам новостроечных исследований от Приазовья до Днепра) / Ю.В.Болтрик // Советская археология. - 1990. - № 4. - С. 30-44.

8. Брашинский, И. Б. Греческий керамический импорт на Нижнем Дону в V-III вв. до н. э. / И. Б. Брашинский. - Л. : Наука, 1980. - 268 с.

9. Брашинский, И. Б. Методы исследования античной торговли (на примере Северного Причерноморья) / И. Б. Брашинский. - Л. : Наука, 1984. - 248 с.

10. Вантит. Изучение микрорегиона памятников у северной окраины г. Воронежа / А. Д. Пряхин, В. И. Беседин, Ю. Д. Разуваев, М. В. Цыбин. Воронеж : Изд-во Воронежского госуниверситета, 1997. - Вып. 1. - 43 с.

11. Граков, Б. Н. Скифы / Б. Н. Граков. - М. : Изд-во Московского университета, 1971. - 200 с.

12. Гуляев, В. И. На восточных рубежах Скифии (древности донских скифов) / В. И. Гуляев. М. : Институт археологии РАН, 2010. - 344 с.

13. Задников, С. А. Торговые связи Бельского городища с античными городами Северного Причерноморья / С. А. Задников // Феномен Більського городища: збереження, дослідження та популярзація найбільшої в Свропі пам'ятки доби ранього залізного віку : збірник наукових праць та матеріалів наукової конференції. - Київ, 2012. - С. 40-42.

14. Зеест, И. Б. Керамическая тара Боспора (Материалы и исследования по археологии СССР. № 83) / И. Б. Зеест. - М. : Изд-во АН СССР, 1960. - 180 с.

15. Книга Большому Чертежу. - М. ; Л. : Изд-во AHCCCP, 1950. - $230 \mathrm{c}$.

16. Корепанов, К. И. Методические вопросы изучения жилищ среднедонской культуры скифского времени / К. И. Корепанов // Теория и методика исследований археологических памятников лесостепной зоны : тез. докл. науч. конф. - Липецк : ЛГПИ, 1992.- С. 161-163.

17. Либеров, П. Д. Проблема будинов и гелонов в свете новых археологических данных / П. Д. Либеров // Население Среднего Дона в скифское время (Материалы и исследования по археологии СССР. № 151). - М. : Наука, 1969. - С. 5-26.

18. Медведев, А. П. Городище скифского времени Верхняя Покровка II / А. П. Медведев // Древности Днепровского Левобережья от каменного века до позднего средневековья (к 80-летию со дня рождения А.И. Пузиковой) : материалы и исследования по археологии Днепровского левобережья. Вып. IV. - Курск : Курская городская типография, 2012. - C. 136-141.

19. Медведев, А. П. Городище Чертовицкое 2 / А. П. Медведев // Исследования памятников археологии Восточной Европы. - Воронеж : Изд-во Воронежского пединститута, 1988. - С. 111-117.

20. Медведев, А. П. Отчет скифо-сарматского отряда археологической экспедиции Воронежского университета за 1985 год / А. П. Медведев // Архив Института археологии РАН. - Р. 1. - № 10735.

21. Медведев, А. П. Охранные исследования памятников раннего железного века у северной окраины города Воронежа в 2010 г. / А. П. Медведев, М. В. Цыбин // Археология и охрана археологического наследия Центральной России. - Воронеж : Изд. дом Воронежского государственного университета, 2014. - С. 71-89.

22. Медведев, А. П. Ранний железный век лесостепного Подонья. Археология и этнокультурная история І тысячелетия до н. э. / А. П. Медведев. М. : Наука, 1999. - 160 с.

23. Медведев, А. П. Река Танаис в системе историко-археологических реалий скифского времени / А. П. Медведев // Античная цивилизация и варварский мир : материалы III археол. семинара / отв. ред. Б. А. Раев. - Новочеркасск : Музей истории донского казачества : КемГУ, 1992. - Ч. II. - С. 127-137.

24. Медведев, А. П. ІІІ Чертовицкое городище (материалы 1-й половины I тыс. н. э.) / А. П. Медведев // Археологические памятники Верхнего Подонья первой половины I тысячелетия н. э. Археоло- 
гия восточноевропейской лесостепи. - Воронеж : Изд-во Воронежского госуниверситета, 1998. Вып. 12.-С. 42-84.

25. Меркулов, А. Н. Поселение 2 у хут. Титчиха на Среднем Дону (исследования 2016 г.) / А. Н. Меркулов // История: факты и символы. - 2017. - Вып. 2. C. $81-89$.

26. Москаленко, А. Н. Раскопки на Архангельском городище в 1952-1953 гг. / А. Н. Москаленко // Краткие сообщения Института истории материальной культуры. - 1956. - № 62. - С. 84-94.

27. Пряхин, А. Д. Семилукское городище позднескифского времени на р. Дон (основные результаты раскопок 1984-1993 г.) / А. Д. Пряхин, Ю. Д. Разуваев // Археологические памятники Среднего Поочья. - Рязань : Научно-производственный центр по охране и использованию памятников истории и культуры Рязанской области, 1995. - Вып. 4. - С. 43-68.

28. Пузикова, А. И. Поселения Среднего Дона / А. И. Пузикова // Население Среднего Дона в скифское время (Материалы и исследования по археологии СССР. № 151). - М. : Наука, 1969. - С. 41-81.

29. Разуваев, Ю. Д. Городище V века до н.э. у с. Петино на Верхнем Дону/ Ю. Д. Разуваев // Вестник Воронежского государственного университета. Серия «История. Политология. Социология». 2016. - № 1. - С. 77-82.

30. Разуваев, Ю. Д. Отчет о раскопках городищ в Верхнем Подонье в 2015 г. Ч. I / Ю. Д. Разуваев // Архив Института археологии РАН. - Р. 1. - № 50839.

31. Разуваев, Ю. Д. Поселки городецкой культуры в глубинных районах донской лесостепи / Ю. Д. Разуваев // Известия Саратовского университета. Серия «История. Международные отношения». - 2016. - Т. 16, вып. 2. - С. 206-211.

32. Ростовцев, М. И. Скифия и Боспор. Критическое обозрение памятников литературных и археологических / М. И. Ростовцев. - Л. : Российская академия истории материальной культуры, 1925. - 624 с.

33. Сарапулкина, Т. В. Оборонительные сооружения Стрелецкого городища-2 скифского времени / Т. В. Сарапулкина, В. А. Сарапулкин, А. А. Божко // Восточноевропейские древности : вестн. Острогож. ист.-худож. музея им. И.Н. Крамского. - Вып. 2. Воронеж : Научная книга, 2012. - С. 170-178.

34. Синюк, А. Т. Мостищенский комплекс древних памятников (эпоха бронзы - ранний железный век) / А. Т. Синюк, В. Д. Березуцкий. - Воронеж : Изд-во Воронежского педуниверситета, 2001. $192 \mathrm{c}$.

35. Спицын, А. А. Историко-археологические разыскания. 1. Исконные обитатели Дона и Донца / А. А. Спицын // Журнал Министерства народного просвещения. Новая серия. - 1909. - Ч. ХІХ (янв.). C. 67-79.
36. Шелов, Д. Б. Танаис и Нижний Дон в IIIІ вв. до н. э. / Д. Б. Шелов. - М. : Наука, 1970. - 251 с.

37. Шрамко, Б. А. Бельское городище скифской эпохи (город Гелон). - Киев : Наукова думка, 1987. $-184 \mathrm{c}$.

\section{REFERENCES}

1. Bandurovskiy A.V. O putyakh proniknoveniya antichnogo importa v verkhovya Severskogo Dontsa v skifskuyu epokhu (po materialam raskopok i razvedok poslednikh let) [About Ways of Penetration of Antique Import to Upper Courses of the Seversky Donets to a Scythian Era (On Materials of Excavation and Investigations of the Last Years)]. Arkheologichni vidkrittya v Ukraïni 1999-2000 rr. [Archaeological Opening in Ukraine 1999-2000]. Kiev, Institut arkheologii Natsionalnoy akademii nauk Ukrainy, 2001, pp. 5-10.

2. Bezmaternykh A.E. Antichnye amfory v kurganakh skifskogo vremeni lesostepnogo Dona [Antique Amphoras in Barrows of Scythian Time of Forest-Steppe Don]. Nortsiya, 2004, iss. IV, pp. 178-192.

3. Bezmaternykh A.E. Kosskaya amfora iz r. Bityug Voronezhskoy oblasti [The Cos Amphora from the Bityug River of the Voronezh Region]. Bosporskiy fenomen. Iskusstvo na periferii antichnogo mira. Materialy mezhdunarodnoy nauchnoy konferentsii [Bosporsky Phenomenon. Art on the Periphery of Antiquity. Materials of the International Scientific Conference]. Saint Petersburg, Nestor-Istoriya Publ., 2009, pp. 464-468.

4. Belaya N.N., Shevchenko A.A. Gorodishche Rossoshki I na Srednem Donu [Hillfort of Rossoshki I on the Middle Don]. Kratkie soobshcheniya Instituta arkheologii, 2016, no. 242, pp. 81-95.

5. Biryukov I.E., Razuvaev Yu.D. Gorodishche skifskogo vremeni u s. Kamenka na Verkhnem Donu [Hillfort of Scythian Time at the Village of Kamenka on the Upper Don]. Arkheologicheskie pamyatniki basseyna Dona [Archaeological Monuments of the Basin of Don]. Voronezh, Izd-vo Voronezhskogo pedagogicheskogo un-ta, 2004, pp. 181-191.

6. Biryukov I.E. Otchet otryada po izucheniyu pamyatnikov rannego zheleznogo veka arkheologicheskoy ekspeditsii Lipetskoy gosdirektsii po okhrane kulturnogo naslediya oblasti v $1997 \mathrm{~g}$. [The Report of Group on Studying the Monuments of the Early Iron Age of Archaeological Expedition of the Lipetsk State Directorate on Protection of Region's Cultural Heritage in 1997]. Arkhiv Instituta arkheologii RAN [Archive of Institute of Archaeology of RAS], R. 1, no. 21404.

7. Boltrik Yu.V. Sukhoputnye kommunikatsii Skifii (po materialam novostroechnykh issledovaniy ot Priazovya do Dnepra) [Overland Communications 
of Scythia (on Materials of New-Construction Research from Priazovye to Dnieper)]. Sovetskaya arkheologiya, 1990, no. 4, pp. 30-44.

8. Brashinskiy I.B. Grecheskiy keramicheskiy import na Nizhnem Donu v V-III vv. do n.e. [The Greek Ceramic Import on Lower Don in the 5th-3rd Centuries BC]. Leningrad, Nauka Publ., 1980. 268 p.

9. Brashinskiy I.B. Metody issledovaniya antichnoy torgovli (na primere Severnogo Prichernomorya) [Methods of Studying Antique Trade (on the Example of Northern Black Sea Coast)]. Leningrad, Nauka Publ., 1984. 248 p.

10. Pryakhin A.D., Besedin V.I., Razuvaev Yu.D., et al. Vantit. Izuchenie mikroregiona pamyatnikov $u$ severnoy okrainy g. Voronezha [Vantit. Studying the Microregion of Monuments near the Northern Suburb of Voronezh]. Voronezh, Izd-vo Voronezhskogo gos. un-ta, 1997, iss. $1.43 \mathrm{p}$.

11. Grakov B.N. Skify [Scythians]. Moscow, Izd-vo Moskovskogo un-ta, 1971. 200 p.

12. Gulyaev V.I. Na vostochnykh rubezhakh Skifii (drevnosti donskikh skifov) [At East Boundaries of Scythia (Antiquities of the Don Scythians)]. Moscow, Institut arkheologii RAN, 2010.344 p.

13. Zadnikov S.A. Torgovye svyazi Belskogo gorodishcha s antichnymi gorodami Severnogo Prichernomorya [Trade Connections of the Belsky's Hillfort with the Antique Cities of Northern Black Sea Coast]. Fenomen Bil's'kogo gorodishcha: zberezhennya, doslidzhennya ta populyarzatsiya naybilshoï v Evropi pamyatki dobi ranogo zaliznogo viku. Zbirnik naukovikh prats ta materialiv naukovoï konferentsiï [Phenomenon of the Belsk's Hillfort: Preservation, Research and Promoting the Largest in Europe Monument of the Early Iron Age. Collection of Scientific Works and Materials of Scientific Conference]. Kiev, 2012, pp. 40-42.

14. Zeest I.B. Keramicheskaya tara Bospora [Ceramic Container of Bosporus]. Materialy $i$ issledovaniya po arkheologii SSSR [Materials and Research on Archaeology of the USSR]. Moscow, Izd-vo AN SSSR, 1960, no. 83. 180 p.

15. Kniga Bolshomu Chertezhu [Book to the Big Sketch]. Moscow; Leningrad, Izd-voANSSSR, 1950.230 p.

16. Korepanov K.I. Metodicheskie voprosy izucheniya zhilishch srednedonskoy kultury skifskogo vremeni [Methodical Questions of Studying the Dwellings of Middle Don Culture of Scythian Time]. Teoriya i metodika issledovaniy arkheologicheskikh pamyatnikov lesostepnoy zony. Tezisy dokladov nauchnoy konferentsii [Theory and Technique of Research of Archaeological Monuments of ForestSteppe Zone. Theses of Reports of a Scientific Conference]. Lipetsk, LGPI Publ., 1992, pp. 161-163.

17. Liberov P.D. Problema budinov i gelonov v svete novykh arkheologicheskikh dannykh [The
Problem of Budins and Gelons in the Light of New Archaeological Data]. Naselenie Srednego Dona $v$ skifskoe vremya (Materialy $i$ issledovaniya po arkheologii SSSR, № 151) [The Population of Middle Don in Scythian Time (Materials and Research on Archaeology of the USSR, no. 151)]. Moscow, Nauka Publ., 1969, pp. 5-26.

18. Medvedev A.P. Gorodishche skifskogo vremeni Verkhnyaya Pokrovka II [The Verkhnyaya Pokrovka II Hillfort of the Scythian Time]. Drevnosti Dneprovskogo Levoberezhya ot kamennogo veka do pozdnego srednevekovya ( $k$ 80-letiyu so dnya rozhdeniya A.I. Puzikovoy): Materialy i issledovaniya po arkheologii Dneprovskogo levoberezhya. Vyp. IV [Antiquities of the Dnieper Left Bank from the Stone Age to the Late Middle Ages (to the 80th Anniversary of A.I. Puzikov's Birth): Materials and Research on Archaeology of the Dnieper Left Bank. Iss. IV]. Kursk, Kurskaya gorodskaya tipografiya, 2012, pp. 136-141.

19. Medvedev A.P. Gorodishche Chertovitskoe 2 [The Chertovitskoe 2 Hillfort]. Issledovaniya pamyatnikov arkheologii Vostochnoy Evropy [Research of Monuments of Archaeology of Eastern Europe]. Voronezh, Izd-vo Voronezhskogo pedagogicheskogo un-ta, 1988, pp. 111-117.

20. Medvedev A.P. Otchet skifo-sarmatskogo otryada arkheologicheskoy ekspeditsii Voronezhskogo universiteta za 1985 god [The Report of ScythianSarmatian Group of Archaeological Expedition of the Voronezh University for 1985]. Arkhiv Instituta arkheologii RAN [Archive of Institute of Archaeology of RAS], R. 1, no. 10735.

21. Medvedev A.P., Tsybin M.V. Okhrannye issledovaniya pamyatnikov rannego zheleznogo veka $u$ severnoy okrainy goroda Voronezha v 2010 g. [Protection Research of Monuments of the Early Iron Age at the Northern Suburb of the City of Voronezh in 2010]. Arkheologiya i okhrana arkheologicheskogo naslediya Tsentralnoy Rossii [Archeology and Protection of Archaeological Heritage of the Central Russia]. Voronezh, Izd-vo Voronezhskogo gos. un-ta, 2014, pp. 71-89.

22. Medvedev A.P. Ranniy zheleznyy vek lesostepnogo Podonya. Arkheologiya i etnokulturnaya istoriya I tysyacheletiya do n.e. [Early Iron Age of Forest-Steppe Don. Archaeology and Ethnocultural History of the I Millennium BC]. Moscow, Nauka Publ., 1999. 160 p.

23. Medvedev A.P. Reka Tanais v sisteme istorikoarkheologicheskikh realiy skifskogo vremeni [Tanais River in the System of Historical and Archaeological Realities of Scythian Time]. Antichnaya tsivilizatsiya $i$ varvarskiy mir: materialy III arkheologicheskogo seminara [Antique Civilization and Barbarous World: Materials of the 3rd Archaeological Seminar]. Novocherkassk, Muzey istorii donskogo kazachestva, 1992, Part II, pp. 127-137. 
24. Medvedev A.P. III Chertovitskoe gorodishche (materialy 1-y poloviny I tys. n.e.) [III Chertovitsky Hillfort (Materials of the 1st Half of I Millennium AD)]. Arkheologicheskie pamyatniki Verkhnego Podonya pervoy poloviny I tysyacheletiya n.e. Arkheologiya vostochnoevropeyskoy lesostepi [Archaeological Monuments of Upper Don of the First Half of the I Millennium AD. Archaeology of the East European Forest-Steppe]. Voronezh, Izd-vo Voronezhskogo gos. un-ta, 1998, iss.12, pp. 42-84.

25. Merkulov A.N. Poselenie 2 u khut. Titchikha na Srednem Donu (issledovaniya 2016 g.) [Settlement 2 at the Titchikha Farm on the Middle Don (Research of 2016)]. Istoriya: fakty i simvoly [History: Facts and Symbols], 2017, iss. 2, pp. 81-89.

26. MoskalenkoA.N. Raskopki na Arkhangelskom gorodishche v 1952-1953 gg. [Excavations in the Arkhangelskoe Hillfort in 1952-1953]. Kratkie soobshcheniya Instituta istorii materialnoy kultury, 1956, no. 62, pp. 84-94.

27. Pryakhin A.D., Razuvaev Yu.D. Semilukskoe gorodishche pozdneskifskogo vremeni na r. Don (osnovnye rezultaty raskopok 1984-1993 g.) [Semiluki Hillfort of Late Scythian Time on the Don River (Main Results of Excavations of 1984-1993)]. Arkheologicheskie pamyatniki Srednego Poochya [Archaeological Monuments of the Middle Oka Region]. Ryazan, Nauchno-proizvodstvennyy tsentr po okhrane i ispolzovaniyu pamyatnikov istorii i kultury Ryazanskoy obl., 1995, iss. 4, pp. 43-68.

28. Puzikova A.I. Poseleniya Srednego Dona [Settlements of the Middle Don]. Naselenie Srednego Dona $v$ skifskoe vremya (Materialy i issledovaniya po arkheologii SSSR, № 151) [The Population of Middle Don in Scythian Time (Materials and Research on Archeology of the USSR, no. 151)]. Moscow, Nauka Publ., 1969, pp. 41-81.

29. Razuvaev Yu.D. Gorodishche V veka do n.e. u s. Petino na Verkhnem Donu [Hillfort of the 5th Century BC at the Village of Petino on the Upper Don]. Vestnik Voronezhskogo gosudarstvennogo universiteta. Seriya: Istoriya. Politologiya. Sotsiologiya, 2016, no. 1, pp.77-82.
30. Razuvaev Yu.D. Otchet o raskopkakh gorodishch v Verkhnem Podonye v 2015 g. Ch. I. [The Report on Excavations of Ancient Settlements in the Upper Don in 2015. Part I]. Arkhiv Instituta arkheologii RAN [The Archive of Institute of Archaeology of RAS], R. 1, no. 50839.

31. Razuvaev Yu.D. Poselki gorodetskoy kultury v glubinnykh rayonakh donskoy lesostepi [Settlements of Gorodetz Culture in Deep Areas of the Don ForestSteppe]. Izvestiya Saratovskogo universiteta. Seriya "Istoriya. Mezhdunarodnye otnosheniya", 2016, vol. 16, iss. 2, pp. 206-211.

32. Rostovtsev M.I. Skifiya $i$ Bospor. Kriticheskoe obozrenie pamyatnikov literaturnykh $i$ arkheologicheskikh [Scythia and Bosporus. Critical Review of Literary and Archaeological Monuments]. Leningrad, Rossiyskaya Akademiya istorii materialnoy kultury, 1925.624 p.

33. Sarapulkina T.V., Sarapulkin V.A., BozhkoA.A. Oboronitelnye sooruzheniya Streletskogo gorodishcha-2 skifskogo vremeni [Fortification of Streletsky Hillfort-2 of Scythian Time]. Vestnik Ostrogozhskogo istoriko-khudozhestvennogo muzeya im. I.N. Kramskogo, 2012, iss. 2, pp. 170-178.

34. Sinyuk A.T., Berezutskiy V.D. Mostishchenskiy kompleks drevnikh pamyatnikov (epokha bronzy ranniy zheleznyy vek) [Mostishe's Complex of Ancient Monuments (Bronze Age - Early Iron Age)]. Voronezh, Izd-vo Voronezhskogo pedagogicheskogo un-ta, 2001. $192 \mathrm{p}$.

35. Spitsyn A.A. Istoriko-arkheologicheskie razyskaniya. 1. Iskonnye obitateli Dona i Dontsa [Historical and Archaeological Investigations. 1. Primordial Inhabitants of Don and Donets]. Zhurnal Ministerstva narodnogo prosveshcheniya. Novaya seriya, 1909, Part XIX (January), pp. 67-79.

36. Shelov D.B. Tanais i Nizhniy Don $v I I I-I v v$. do n. e. [Tanais and Lower Don in the 3rd-1st Centuries BC]. Moscow, Nauka Publ., 1970. 251 p.

37. Shramko B.A. Belskoe gorodishche skifskoy epokhi (gorod Gelon) [Belsk Hillfort of Scythian Era (City of Gelon)]. Kiev, Naukova dumka Publ., 1987. 184 p.

\section{Information about the Author}

Yuriy D. Razuvaev, Candidate of Sciences (History), Associate Professor, Department of History of Russia, Voronezh State Pedagogical University, Lenina St., 86, 394043 Voronezh, Russian Federation, razuvaevyd@mail.ru, http://orcid.org/0000-0003-4865-3206.

\section{Информация об авторе}

Юрий Дмитриевич Разуваев, кандидат исторических наук, доцент кафедры истории России, Воронежский государственный педагогический университет, ул. Ленина, 86, 394043 г. Воронеж, Российская Федерация, razuvaevyd@mail.ru, http://orcid.org/0000-0003-4865-3206. 